\title{
Capitalismo, crise e lutas de classes contemporâneas: questões e polêmicas*
}

\section{Capitalism, crisis and contemporary class struggle: issues and controversies}



Marcelo Braz ${ }^{* *}$

Resumo: O texto apresenta questões e polêmicas relacionadas ao momento atual do desenvolvimento capitalista. Divido a exposição em quatro partes que se relacionam entre elas. Uma primeira discute o capitalismo contemporâneo e as condições de sua crise. A segunda mostra os dados reais que condensam o desenvolvimento contraditório capitalista em dois níveis: barbárie e restauração. A terceira parte levanta algumas questões práticas e teóricas para refletir sobre as condições atuais das lutas de classes. Por último, um breve balanço que sugere alguns caminhos.

Palavras-chave: Capitalismo contemporâneo. Crise contemporânea. Lutas de classes. Partido político. Movimentos sociais.

\begin{abstract}
The text presents issues and controversies related to the present moment of capitalist development. Divided the exhibition into four parts that relate to them. The first discusses the conditions of contemporary capitalism and its crisis. The second shows the actual data that condense the contradictory development of capitalism in two levels: barbarism and restoration. The third part raises some practical and theoretical questions to reflect on the current conditions of class struggle. Finally, a brief assessment suggests that some paths.
\end{abstract}

Keywords: Contemporary capitalism. Contemporary crisis. Class struggles. Political party. Social movements.

* Este texto foi preparado a partir da palestra que realizei por ocasião do evento comemorativo do Dia do Assistente Social, promovido pela Cortez Editora com o apoio do Cress-SP, da Abepss e da Enesso, ocorrido no dia 14 de maio de 2012. Sua argumentação central foi originalmente preparada para a exposição da palestra.

** Doutor em Serviço Social pela Universidade Federal do Rio de Janeiro/RJ, Brasil; professor adjunto III da Escola de Serviço Social da UFRJ. Professor e colaborador da ENFF (Escola Nacional Florestan Fernandes).E-mail: reis.braz@ig.com.br. 


\section{Capitalismo contemporâneo: crise e consequências sociais}



i. vivemos a plena madurez do modo de produção capitalista (MPC), o que significa que vivemos a plena barbarização da vida social que se expressa nos indicadores sociais, no padrão destrutivo do desenvolvimento das forças produtivas e na financeirização do capital, como procurou demonstrar José P. Netto; ${ }^{1}$

ii. a natureza tardo-periférica do Brasil não coloca nenhum óbice ao desenvolvimento dos traços deletérios do MPC entre nós; antes os potencializa, pois que se combinam com as heranças arcaicas que persistem no país, como apontou Josiane S. Santos; ${ }^{2}$

iii. vivemos uma quadra contrarrevolucionária que se expressa na dificuldade de construção de um projeto societário alternativo, ainda que estejamos adentrando uma curva ascendente das lutas de classes nos centro do capitalismo com reflexos no Brasil, como procurarei problematizar.

Do primeiro pressuposto retomarei algumas questões da contribuição de Netto, procurando realçar aquelas que incidirão sobre a temática que me cabe na mesa. Especificamente, partilho de suas análise e corroboro os números apontados, mas adicionaria outros mais à frente que, creio, ajudarão a reafirmar o caráter atual da crise do capital. Passemos a tratar exatamente dela.

\section{Capitalismo: mais-valia, mais crise e mais barbárie}

A crise capitalista atual não nos conduzirá à superação da ordem burguesa. $\mathrm{O}$ capitalismo, por si só, sempre dará em mais capitalismo. A natureza da crise do

1. Netto tratou na mesa exatamente do capitalismo contemporâneo, discutindo os elementos que potencializam a crise e indicando os traços que conformam a barbárie que caracteriza os desdobramentos sociais da ordem do capital.

2. Josiane S. Santos discutiu a formação social brasileira procurando relacioná-la à dinâmica do capitalismo contemporâneo e modo como se expressa a "questão social" no Brasil. 
capital que se aprofundou a partir de 2008 não é diferente, em sua essência, das crises que abateram o sistema em tantas outras vezes, tipificadas pelos traços constitutivos do estágio imperialista ${ }^{3}$ que se estruturou justamente a partir de outra grande e grave crise, a de 1873. Ela é movida pela natureza contraditótia do desenvolvimento capitalista que, ao potencializar seu processo de reprodução ampliada (sua própria acumulação de capital), reproduz os fatores que exponenciam suas contradições e acionam crises que, desde as últimas décadas do século XX, têm maior duração e se exprimem em períodos menos espaçados (e sem ondas longas expansivas), alternando períodos (espasmódicos) de crescimento, auge, crise, recessão/depressão, retomada...

A contradição central (a produção social e a apropriação privada) e o caráter anárquico da produção potencializam e assentam o desdobramento das crises capitalistas que podem se expressar na tendência de queda da taxa média de lucro e/ou na combinação superprodução de mercadorias/subconsumo das massas trabalhadoras. E é o aumento da população sobrante (do exército industrial de reserva) e a massa de capitais excedentes que encontra dificuldades para se valorizar (a superacumulação) que têm tornado o metabolismo social do capital ainda mais sedento e voraz na busca de novos espaços de acumulação e de valorização do valor. A análise de Mandel é formidável porque é a que melhor aponta esses elementos como aqueles que comandam o capitalismo tardio, indicando as questões centrais para pensar o capitalismo contemporâneo, especialmente duas: o aumento da composição orgânica do capital e o problema da crescente prevalência do capital constante sobre o variável e, decorrente daí, a tendência de redução do trabalho vivo e o problema da relação criação/realização da mais-valia.

Além desses fatores macroestruturais, a especificidade da crise atual, analisada com rigor por Mészáros, está assentada em duas características intrísecas e que também se expressam na dinâmica estrutural do MPC contemporâneo: ela acentua o caráter destrutivo da produção capitalista, de modo que o metabolismo social comandado pelas forças do capital faz predominar, de maneira incomparável, tendências altamente destruidoras da exploração da natureza que concorrem até mesmo para criar sérios obstáculos à própria reprodução da vida social; por outro lado,

3. Tais traços são aqueles trabalhados por Lenin, no seu clássico Imperialismo - fase superior do capitalismo: a exportação de capitais, a formação de monopólios industriais e bancários e a tendência progressiva de associação/fusão entre eles originando o capital financeiro, a formação e o controle de um moderno sistema de crédito, a centralização financeira do capital que faz surgir uma oligarquia financeira controladora de uma massa de capitais monumental; em decorrência, estrutura-se uma verdadeira partilha econômica (entre os grandes grupos monopolistas) e territorial (entre os países imperialistas sedes dos monopólios). 
e correlatamente, esgotaram-se os mecanismos estruturais (posto que os paliativos sempre hão de existir) de autorregulação do sistema sociometabólico do capital, uma vez que o caráter permanente da crise sobressai em detrimento da sua forma cíclica de se expressar, prevalente até os anos 1970. Mészáros caracteriza muito bem a crise adjetivando-a, corretamente a meu ver, como uma rastejante.

Aqui, quero salientar duas observações: a primeira diz respeito à predominância de análises catastrofistas sobre a crise contemporânea. A sua forma a-histórica de apreender a realidade só conduzirá a "saídas" igualmente a-históricas que podem se expressar em promessas voluntaristas, como as que pululam nos países centrais tocadas pela "juventude indignada" dos setores pequeno-burgueses das grandes cidades e pelos ecoambientalistas de todo tipo; ou em "soluções" fatalistas que podem dar tanto nas promessas que promovem a (improvável) ruptura abrupta com a ordem burguesa baseada em prognoses fantásticas sobre o futuro (e, evidentemente, numa equivocada análise do presente) ou, ao contrário, podem resultar no mais absoluto niilismo, inofensivo e inepto.

Mesmo que não possamos debitar à teoria o rumo de algumas das expressões das lutas sociais, é certo que ela representa parte do esforço de autores que, ainda que não possam ser responsabilizados por seus rumos, mantêm notória influência nesse campo. São vários os exemplos que podemos colecionar, mesmo que partam de perspecivas teóricas diversas, que podem nos levar a caminhos diferentes: desde Kurz nos anos 1990, passando por Negri/Hardt na década de 2000 e pelos diversos estudos que colocam o acento na questão ambiental (que é de fato uma questão relevante, mas não a central) como o que se faz notar dos textos de Boaventura Sousa Santos.

A segunda observação diz respeito às correntes que não entendem a natureza da crise contemporânea e que acabam compreendendo-a como mais uma crise do capital, passível de solução, regulação ou medidas anticíclicas. Aqui aposta-se na administração de uma dinâmica que é cada vez mais incontrolável e que já não mais comporta formas de autorregulação. Pior: aposta-se no controle e na administração das consequências sociais do inadministrável sistema do capital. Vê-se tal equívoco nas correntes que apostam numa terceira via tardia, nas saídas ditas neokeynesianas (que no Brasil têm atendido pelo nome de neodesenvolvimentismo que se expressa, na verdade, como um arremedo do modelo desenvolvimentista) ou até mesmo no sonho de uma reedição saudosa de um novo Welfare State.

O suposto neodesenvolvimentismo, quando comparado aos traços gerais das políticas desenvolvimentistas — que, de modo muito problemático e diferenciado, conhecemos ao longo do período 1930 e 1980 no Brasil através de algumas expe- 
riências implementadas - está muito longe do modelo original. Segundo especialistas, quando comparado ao paradigma desenvolvimentista que se conheceu no século passado, a hipótese neodesenvolvimentista "se desmancha no ar", e as razões são claríssimas, seja porque: "a) apresenta taxas de crescimento bem mais modestas; ${ }^{4}$ b) confere importância menor ao mercado interno, isto é, ao consumo das massas trabalhadoras; c) dispõe de menor capacidade de distribuir renda ${ }^{5}$; d) aceita a antiga divisão internacional do trabalho, promovendo uma reativação, em condições históricas novas, da função primário-exportadora do capitalismo brasileiro; ${ }^{6} \mathrm{e}$ ) é dirigida politicamente por uma fração burguesa, a qual denominamos burguesia interna, que perdeu toda a veleidade de agir como força antiimperialista".

Para além das muitas polêmicas que o tema suscita, uma definição empregada para explicar o que chamo de hipótese desenvolvimentista é esclarecedora: “[...] o neodesenvolvimentismo é o desenvolvimento possível dentro do modelo capitalista neoliberal [...]". ${ }^{8}$ Ora, sabemos que o neoliberalismo se caracteriza justamente por políticas e medidas que obstam o desenvolvimento e o crescimento econômico, tornando muito difícil sustentar tal afirmação.

Ainda sobre a segunda observação: o entendimento do capitalismo contemprâneo parece ser levado para um beco sem saída, justamente porque mostram-se inúteis as saídas de administrá-la. Namora-se o capital, imperando o possibilismo que procura agir nos espaços cada vez mais estreitos e restritos e que atua nas supostas brechas por dentro do Estado capitalista. O trabalho torna-se parceiro do capital e seus representantes, os representantes do capitalismo nos governos.

4. Lembre-se que um dos pilares do desenvolvimentismo é justamente a robustez do crescimento econômico.

5. Mercado interno forte e amplo, dinamizado por políticas de distribuição de renda que, entre outras funções, ajudam a potencializar o consumo das massas: eis aí dois pilares do modelo original que não se sustentam na hipótese neodesenvolvimentista.

6. Aceitação absolutamente inaceitável no modelo "clássico"!

7. O tão desejado caráter progressista da burguesia nacional se esfumaçou em 1964 e, hoje, ela está perfeitamente integrada, associada e dependente aos circuitos comandados pelo grande capital operante no país. As citações às quais recorri se referem a uma parte da entrevista de Armando Boito Jr. ao Jornal Brasil de Fato (5 a 11/4/2012). É importante salientar que o autor tem conclusões diferentes das minhas em relação ao alcance do que chamo de hipótese neodesenvolvimentista (deve-se considerar aqui os limites que uma entrevista coloca para uma argumentação mais sólida). Para ele, apesar dos óbices e dos limites atuais, tão bem apontados no trecho reproduzido acima, é possível sustentar o neodesenvolvimentismo que inclusive aponta, politicamente, para a formação de uma "frente política neodesenvolvimentista" formada em torno de grupos sociais muito heterogêneos que disputam o governo Dilma Roussef e que se unem pela oposição aos grupos (predominantemente ligados ao PSDB e ao DEM) neoliberais ortodoxos.

8. Brasil de Fato (Idem). 
Busca-se a hegemonia em comunhão com os interesses maiores do capital que faz do Estado e dos governos de plantão seus prepostos, consolidando aquilo que Franscisco de Oliveira (2007) denominou de "hegemonia às avessas", pela qual a esquerda exerce o poder para realizar o projeto do capital, por intermédio de meios políticos que rebaixam sobremaneira seus horizontes. Ela (a "hegemonia às avessas") é recente entre nós e começou em 2003, mas é velha conhecida dos europeus cujos governos tocados por partidos socialistas desde os anos 1980 são os melhores exemplos. Recorde-se dos casos francês (com Mitterrand), espanhol (com Gonzales) e português (com Soares).

\section{$\|$}

\section{Crise do capitalismo: barbárie e restauração}

Diferentemente do que disseram os apologetas do capital, o pleno desenvolvimento da ordem burguesa não produziu igualdade. Pelo contrário, gerou mais desigualdades, tanto entre os países centrais e os da periferia, quanto no interior de cada nação em que as assimetrias sociais foram aumentadas. Na relação entre os países, tal fato é verificável por dados insofismáveis que atestam que $80 \%$ da população que vive no Hemisfério Sul dispõe de $20 \%$ da riqueza mundial, ao mesmo tempo em que a outra parte, menos de $20 \%$ da população que vive no Hemisfério Norte, desfruta de $80 \%$ da riqueza.

Os países de alta renda, onde vive $16 \%$ da população, concentram $55 \%$ da produção mundial. Por outro lado, os países de renda baixa e média, que abrigam $84 \%$ da população mundial, respondem por $45 \%$ da produção global. Os dados relativos à renda são sempre insuficientes para dar conta da realidade social que caracteriza a relação produção/distribuição da riqueza no mundo capitalista. Mesmo assim, veja-se os seguintes números:

- considerando-se os cerca de 47 mil dólares que expressam a renda dos mais ricos e os 2.300 dólares que cabem aos mais pobres, a renda per capita destes corresponde a apenas $5 \%$ da dos mais ricos;

- a renda per capita dos Estados Unidos é 4,2 vezes maior do que a renda média mundial e 21 vezes maior do que a renda média da África Subsaariana; 
Para além da renda, vejamos outros dados:

- 1/6 da humanidade passa fome (e entre estes, 852 milhões sofrem fome crônica) enquanto, segundo dados da FAO (Fundo para Agricultura e Alimentação - ONU), a produção de alimentos atual é capaz de alimentar 11 bilhões de pessoas, quase duas vezes a população mundial. Note-se que do 1 bilhão dos famintos, $75 \%$ deles estão no campo. É digno de nota também que o problema da sociedade do capital não se resume aos aspectos quantitativos, pois que há problemas qualitativos graves: há hoje no mundo capitalista cerca 1 bilhão de obesos.

- A subnutrição acomete uma entre três crianças no mundo. Em números absolutos, a subnutrição e a fome crônica afetam aproximadamente 250 milhões de pessoas na Índia; mais de 220 milhões na África; 40 milhões em Bangladesh; 22 milhões no Brasil, 15 milhões no Afeganistão. Morrem cerca de 9 milhões de pessoas por ano devido a complicações relacionadas à fome ou aproximadamente 25 mil mortes por dia.

- De acordo com a FAO, entre 1950 e 2000, a produção mundial de grãos mais que triplicou, passando de cerca de 590 milhões para mais de 2 trilhões de toneladas métricas ao ano. Menos da metade dos grãos hoje é destinada à alimentação, enquanto a maior parte serve para fabricar rações animais, biocombustíveis e outros produtos industriais. O desperdício na produção de alimentos beira cifras injustificáveis de $30 \%$ a $40 \%$ da produção de grãos.

- Segundo a mesma FAO, praticamente a metade da população vive abaixo da faixa de pobreza e, nesse universo, 1 bilhão de pessoas vivem com menos de um dólar diário.

- Mas não é um mal apenas dos países menos desenvolvidos do continente. Nos Estados Unidos, o nível de pobreza chegou o ano passado a 14,3\%. Em nível mundial, de acordo com a ONU, há sete países que somam dois terços da pobreza e fome do mundo: Bangladesh, China, Índia, Indonésia, Paquistão, Congo, e Etiópia. Na Europa, segundo a agência estatística europeia, há 84 milhões de pobres, $17 \%$ da população.

- $30 \%$ da população vive problemas crônicos com o consumo da água, e a ONU admite que até 2050 cerca de $60 \%$ terá graves dificuldades de acesso à água.

- Segundo estudos da Royal Society, uma criança de um país rico consome de 30 a 50 vezes mais água do que uma criança de um país pobre. 
- Na América Latina, segundo dados da ONU, 168 milhões vivem abaixo da faixa de pobreza, e os que vivem na pobreza extrema, aqueles com renda inferior a dois dólares diários, são hoje cerca de 85 milhões de latino-americanos.

- No Brasil, segundo dados de Pochmann et al. (2005, p. 11), identificou-se no contingente de 5 mil famílias (aproximadamente $0,01 \%$ da população brasileira), a conformação de um volume patrimonial equivalente a $42 \%$ de todo o PIB brasileiro.

O desenvolvimento atual das forças produtivas não tem parâmetros. Em meados do século XIX Marx e Engels afirmavam que o modo de produção capitalista já havia produzido riquezas num volume de excedentes maior que todas as outras épocas juntas. A "imensa coleção de mercadorias" do mundo capitalista contemporâneo demanda um grau muito acentuado de exploração da natureza que requer grande mobilização das forças sociais do trabalho num patamar de desenvolvimento sem par na história, tornando o debate do fim do trabalho e da sua centralidade um exercício ilógico de metafísica. Alguns dados ilustram:

- Hoje aumentou extraordinariamente a extração mineral da natureza. Além da extração cada vez maior do petróleo e do minério de ferro, bases fundamentais das matérias-primas que servem às mercadorias capitalistas, registre-se o aumento considerável da extração de minerais voltados para as mercadorias tecnológicas: a extração de lítio (que o diga a Bolívia), de tântalo e a de nióbio aumentou extraordinariamente. No caso do nióbio, ente 1960 e 2007, a produção aumentou 77 vezes. No mesmo período, quadruplicou a de cobre e de chumbo (Royal Society).

- Segundo especialistas, se continuarmos nesse ritmo para atender aos padrões de consumo atuais, e se a massa populacional da China, da Índia, do Brasil e de alguns países africanos (como a África do Sul) consumir em proporções mais ou menos semelhantes à dos países centrais, precisaremos de pelo menos mais dois planetas Terra para suprir essa demanda.

Por outro lado, a financeirização do capital resulta numa massa de valores excedentes que torna a superacumulação um fenômeno sistêmico e não acidental no atual período do imperialismo. Tal massa de valores tem encontrado, fundamentalmente, quatro formas de se valorizar:

a) migrando para áreas ainda inexploradas que podem fornecer novos espaços de acumulação de capital, especialmente para os segmentos, ainda 
não explorados do setor de serviços (saúde, educação e previdência), em geral a cargo do Estado, nos quais o montante de mais-valia extraída do trabalho vivo se valoriza através de meios que mercantilizam os diversos níveis da vida social, ao mesmo tempo em que podem ser espaços fecundos para, segundo os termos de Mandel, transformar serviços (sociais, culturais) em mercadorias, industrializando-os. O setor de segurança privada também se destaca aqui como espaço promissor de valorização do capital, enquadrando-se nas esferas vinculadas à produção bélica, como veremos adiante;

b) avançando sobre a natureza, no sentido de industrializar e mercantilizar os recursos naturais — não é à toa que a Nestlé e a Coca-Cola tentam no âmbito da OIT tornar a água um bem energético que a torne commodity; e não é à toa que estamos assistindo, em pleno século XXI, à pilhagem contemporânea de terras e recursos naturais dos países periféricos por parte de grandes grupos do capital financeiro. Na América Latina, isto avança sobretudo na rica região amazônica, mas não apenas nela. No Uruguai, por exemplo, toda a superfície florestal é propriedade de apenas três empresas (Brasil de Fato, maio/2012). Outro dado importante: em 2011, 57\% dos investimentos estrangeiros recebidos pela América do Sul (sem contar o Brasil) foram dirigidos ao setor de recursos naturais (Idem); ${ }^{9}$

c) investindo nos setores rentistas, preferencialmente nos segmentos de renda fixa que melhor remuneram o capital, como os títulos das dívidas públicas de países como o Brasil onde quase metade do orçamento federal está comprometida com o pagamento dos serviços da dívida (juros e amortizações);

d) ou, ainda, investindo na produção de artefatos bélicos, o que supõe a criação de conflitos e guerras que possam animar a indústria bélica e que possam ser espaços de destruição de forças produtivas. Aqui, reitere-se o papel da segurança privada, profícuo para a potenciação de armamentos e acessórios sofisticados voltados para o uso civil e para a prestação de serviços de segurança. As mercadorias que daí decorrem são diversas: vão

9. Esses são apenas alguns números referentes a essa àrea cuja expansão do capital tem sido avassaladora, como mostram os dados. As preocupações ambientais, para além das mais catastrofistas, são absolutamente pertinentes, uma vez que se a produção destrutiva capitalista continuar avançando pelas próximas décadas na mesma toada com que se desenvolveu na segunda metade do século XX até nossos dias, é bem provável que teremos seriíssimas dificuldades de manutenção das condições da vida humana para o século XXII. 
desde automóveis blindados, circuitos de segurança doméstica e empresarial, aumento da produção de armas para uso pessoal, fornecimento de equipamentos desenvolvidos por Forças Armadas nacionais (a de Israel, principalmente), cuja tecnologia é transladada para as forças policiais (as do Rio de Janeiro e as de São Paulo têm sido compradores regulares) que as adquirem como mercadorias voltadas para funções repressivas contra seus próprios cidadãos. Registre-se ainda o universo não contabilizado oficialmente pelo tráfico de armas feito por pessoas ligadas a grandes empresas e a governos; ou, ainda, as diversas e crescentes forças paramilitares que atuam como milícias privadas a serviço da burguesia e de seus governos, presentes em países que vivem/viveram recentemente golpes/ invasões das forças imperialistas, como são os casos do Iraque, da Líbia e, ao que tudo indica, da Síria. De modo diverso é o que se vê também no Estado protofascista colombiano, em alguns países africanos, ricos em recursos minerais, que vivem zonas de conflito potencializadas pelas nações imperialistas. Registre-se, também, o que ocorre em grandes cidades conflagradas por milícias ligadas a grandes grupos traficantes de drogas enraizados nas estruturas de poder, como são os casos, entre tantos, de algumas regiões da Itália, do Japão, dos EUA, do México e do Brasil.

Diante de tal quadro, que apenas esboçei aqui em seus traços gerais de crise e suas consequências, quais seriam as possilidades concretas para o reverso dessa realidade sombria? Num contexto em que ainda parece predominar uma tendência contrarrevolucionária é possível cogitar a construção de um projeto societário alternativo?

\section{III}

\section{Por onde andam as lutas de classes?}

O século XXI trouxe consigo a expectativa, entre os segmentos da esquerda mundial, de superação da curva descendente das lutas de classes. De fato, o desfecho do século foi o pior possível. A ideologia neoliberal ainda gozava de relativa força no mundo. Os movimentos socialista e comunista apenas começavam a se reerguer da avalanche que desmoronou sobre eles com a queda do Muro e com o fim da experiência soviética. 
Para além dos exemplos de resistência à agenda regressiva do neoliberalismo - como foram os casos das lutas antiglobalização e das lutas nacionais contra as políticas neoliberais: recorde-se da emblemática experiência do Partido dos Trabalhadores no Brasil - , foram as lutas em torno do movimento bolivariano (Venezuela, Bolívia e Equador) que retomaram a ofensiva dos trabalhadores, iniciando um movimento de deslocamento da curva descendente das lutas de classes. Passou-se a imaginar que elas seriam portadoras de conteúdos para se pensar num "socialismo do século XXI", como discute Atílio Borón (2010).

Ao mesmo tempo, adentramos a atual década sob os efeitos da crise que irrompeu em 2008 levando consigo empregos, salários, direitos e trilhões de dólares. Seus desdobramentos ainda estão por se apurar, mas já há dados que mostram que, sob todos os ângulos, as consequências sociais acometem brutalmente os trabalhadores em todo o mundo, mesmo sabendo que o epicentro da crise esteja nos países centrais (primeiro, em 2008-2009, nos EUA; e, a partir de 2011, na Europa). Há protestos em todo o mundo. Greves aparecem em todo canto. A classe trabalhadora, enfim, se rearticula para uma luta que até aqui é defensiva. Entretanto, entre todas as mobilizações às quais assistimos desde 2008, aquelas que mais se destacaram, que gozaram de maior repercussão e que envolveram um número maior de sujeitos foram as que culminaram na ocupação de espaços públicos próximos aos centros financeiros, como em Wall Street. Logo chamado de Occupy, suas lideranças autodenominaram-se "indignados", abdicando de hierarquias entre os líderes, abrindo mão de métodos considerados "arcaicos" de fazer política e apontando para horizontes que não vislumbram a ruptura com o capitalismo (ainda que o condenem) e nem a perpectiva de construção de uma outra sociedade.

Este sucinto quadro caracteriza o momento atual das lutas de classes. Ele nos indica que não há no seu horizonte a articulação de um projeto societário alternativo ao do capital, ainda que este seja repudiado tanto entre as lutas defensivas e de resistência dos trabalhadores quanto entre as mobilizações dos chamados "indignados". O difuso "socialismo do século XXI" expressa-se mais como um conjunto de princípios ${ }^{10}$ (que devem ser considerados!) que podem, no máximo, nortear agendas de lutas contra o capital em favor do trabalho, apontando para uma articulação anti-imperialista, o que, deve-se esclarecer já é um grande passo.

Para avançarmos, comecemos por demarcar uma distinção que é essencial: $a$ ausência de projeto societário alternativo não significa a ausência de lutas de classes. A questão é saber qual o patamar atual das lutas de classes para saber o que

10. Uma leitura do livro preparado pelo intelectual militante Atílio Borón (2010) nos dá essa clara noção. 
elas podem produzir. O que podemos dizer, com toda a certeza, é que o que todos os analistas concordam: a partir dos anos 1990 as lutas de classes esmoreceram junto com a crise em que mergulharam as esquerdas.

E isso não foi à toa! A dissolução das experiências socialistas lançou-nos numa profunda crise e abriu as vias para a hegemonia incomparável das forças do capital, estabelecendo uma onda longa contrarrevolucionária que passamos a viver.

Vivemos um tempo histórico que abriu as portas para uma onda conservadora na qual navegam duas formas de conservadorismo: um conservadorismo de direita e um conservadorismo de esquerda, ambos resultantes de uma cultura própria do capitalismo contemporâneo que se coaduna na ideologia pós-moderna.

O primeiro, o de direita, afirma o fim da história. E o segundo, o de esquerda, afunda no possibilismo pragmático que namora o capital, apontado anteriormente.

A tarefa (individual e coletiva) de superar esse tempo histórico - que Agustín Cueva chamou de tempos conservadores - pela teoria, se reafirma pela clareza de que "sem teoria revolucionária não há movimento revolucinário" (Lênin). Entretanto, tal tarefa teórica não poderia sucumbir a três riscos altíssimos: o primeiro seria o de se limitar a uma tácita aceitação dos limites do nosso tempo, caracterizando um claro conformismo; o segundo, aquele cujo resultado estaria aquém do seu próprio tempo, incorrendo em tentativas saudosistas de reeditar formas pretéritas que, de forma anacrônica, procuram apenas voltar ao passado (é a "poesia do passado" de que falava Marx no 18 Brumário de Luís Bonaparte); e o terceiro, aquele no qual o resultado seria uma vã tentativa de ir além do seu tempo (recordemos Hegel: "ninguém é maior que seu tempo. É possível apenas ser melhor que seu tempo"), incorrendo em elaborações fantasiosas, que se sustentam na prognose de um futuro mágico.

Aqui, o risco seria o de construir uma teoria e um projeto em que a frase se apresenta maior que o conteúdo, bem como refletiu Marx no 18 Brumário acerca das ilusões utópicas: "A revolução do século XIX tem que deixar os mortos enterrarem seus mortos, para chegar ao seu próprio conteúdo". Ou seja, a superação de que fala Marx se exprime na necessidade de uma teoria revolucionária que, como escrevera antes com Engels, na Sagrada Família, só "se tornará força material se se apoderar das massas", como expressão de suas necessidades sociais históricas. Ou seja, a revolução do século XXI também "tem que deixar os mortos enterrarem seus mortos para chegar ao seu próprio conteúdo".

Tem toda a razão José Paulo Netto quando diz que o problema das esquerdas está no plano da organização política, o que nos lega um verdadeiro "deficit orga- 
nizacional" que só pode ser superado se conseguirmos encontrar meios de luta adequados aos nossos tempos. Entretanto, precisamos continuar avançando na compreensão (teórica) do momento histórico para acertar na prática política, atentando-se para a observação de Togliatti acerca do peso dos acertos (e dos erros) na análise e na ação, citada parágrafos atrás.

Nesse sentido, ainda é insuficiente o conhecimento sobre a morfologia atual do proletariado (especialmente a análise de até onde vai a ampliação do "trabalhador coletivo" da grande indústria, questão decisiva para pensar o sujeito da revolução), como também ainda não há acúmulo suficiente para entender as formas de lutas atuais que têm produzido inúmeros novos sujeitos coletivos.

O fato incontestável que temos de analisar é que desde os anos 1970, com mais intensidade a partir dos anos 1990, produziram-se lutas sociais que diversificaram enormemente o universo que se conhecia até então. De lá pra cá, colecionamos mais derrotas que vitórias, mas o universo se ampliou consideravelmente, envolvendo desde lutas fabris até as mais variadas lutas, passando por questões culturais, étnicas e ambientais. De Seatle ao Ocuppy W. Street, dos zapatistas à luta dos sem-terra no Brasil, passando pelos piqueteiros da Argentina, por Oaxaca no México e pelas lutas altermundistas (antiglobalização) nos países centrais até os recentíssimos mal chamados "movimento dos indignados", colecionamos não só derrotas, mas também exemplos concretos do perfil das lutas de classes contemporâneas.

Aqui reside um "problema" que devemos enfrentar, ou pelo menos situá-lo. Ele aparece como problema teórico-conceitual que tem a ver com a busca em dar nomes aos "exemplos concretos do perfil das lutas de classes". Até que ponto os conceitos criados por pesquisadores das ciências sociais especializadas (sociólogos, cientistas políticos e antropólogos), filiados às mais diferentes perspectivas teóricas, explicam a realidade? E até que ponto os mesmos conceitos podem servir para ocultar ou até mesmo mistificar a mesma realidade que pretensamente dizem explicar? Cada nova conjuntura origina um novo conceito para designar um novo sujeito coletivo surgido das lutas de classes... Essa busca por conceituar a sempre mutante luta de classes não nos parece uma tormenta sem fim?

\section{Para onde vão as lutas de classes? 0 tormento de Sísifo das Ciências Sociais}

Se nos voltarmos para o debate que as Ciências Sociais vêm desenvolvendo desde a década de 1960, veremos que os diversos estudiosos das chamadas "lutas 
sociais" se esmeraram por denominá-las e classificá-las usando conceitos diversos que variaram ao gosto dos analistas. A cada nova mudança na conjuntura, um novo conceito surgia para designar o "novo sujeito" que entrava em cena, o "novo palco" das lutas, as "novas especificidades" que as moviam.

Sem dúvida que esse é o papel dos cientistas sociais e que as "lutas sociais", os "novos sujeitos" etc. são parte da "matéria-prima" das obras que criam com suas pesquisas. Entretanto, o que mais chama a atenção aqui é o fato de que quanto mais se esforçavam para entender o novo que lhes reluzia os olhos, mais se afastavam da possibilidade de revelar a estrutura que ele esconde. Quanto mais se empenhavam por criar novos conceitos, mais estes serviam como véu que encobre a essência, acabando por reforçar sua "aparência enganadora". À medida que criavam um novo conceito, surgia um novo sujeito em uma nova conjuntura que demandava outro conceito, reproduzindo assim um tormento que lembra o de Sísifo. ${ }^{11}$

A tormenta se renova a cada época. Basta uma nova onda conjuntural de crises capitalistas (que aparece muitas vezes desgarrada de sua crise que é, em si, estrutural), que sempre produzem contestações pelos quatro cantos do mundo, para que uma nova onda de conceituações surja anunciando a novíssima cena contemporânea. A mais nova vem de 2008-2009, e o esmero está em entender o que significam as lutas que pipocaram nos países centrais, como as que se deram na Espanha e as que se desenrolaram na ocupação de Wall Street. Em todos os casos, é a luta de classes, essa velhíssima senhora que dá as caras com fisionomias que lhe dão a aparência de nova. Muitas das análises se esforçam, com notável empenho, para identificar o caráter dos movimentos de protesto recentes que vêm sendo denominado de Occupy. Para além dos relatos puramente descritivos que predominam nas redes sociais em muitos dos escritos eletrônicos que circulam, importa anotar que já há a formação de uma incipiente massa crítica que tem envolvido teóricos renomados, reunidos em publicação recente (Harvey at al., 2012).

Não há capitalismo sem lutas de classes. Enquanto as forças do capital predominarem no comando da produção social, as forças do trabalho se insurgirão, de algum modo, para lutar contra a apropriação privada que está na base das relações sociais de produção capitalistas. Ao mesmo tempo em que é a sua contraface indesejada, as lutas de classes funcionam como dínamo que impulsiona as forças do capital para inovações que se voltam contra o trabalho. Capitalismo é luta de classes. Enquanto aquele existir, esta persistirá.

11. Aprofundei esse "problema" em texto recentemente publicado. Cf. Braz, 2012. 
Desde quando emergiu a moderna luta de classes que o jovem Marx já identificava na Miséria da filosofia entre 1846 e 1847 e que surgia como a mola propulsora das contradições da ordem burguesa tal como se lê no Manifesto do Partido Comunista - que sai à luz justamente quando, em 1848, os trabalhadores assumem um nível de consciência de classe inédito - , ela não mais saiu de cena por mais que teimem em não enxergá-la na "nova cena". A burguesia e o proletariado são os seus protagonistas, acompanhados de outros personagens que atuam em circunstâncias específicas, historicamente marcadas. Entre aqueles que se voltam para entender as "lutas sociais" - ou por debilidade teórica ou por interesses meramente ideológicos - predominam os que se atêm nos "atores" coadjuvantes, pouco contribuindo para ir além do limbo que embaça a superfície dos fenômenos. Mesmo que subjetivamente imbuídos em estudar a realidade para conhecê-la melhor, o resultado não é muito mais que a descrição dos fatos, quando não se descamba até mesmo para a mistificação. Para se ter uma ideia, o debate brasileiro em torno dos chamados "novos movimentos sociais" foi capaz de criar, entre o final dos anos 1970 e o início da década de 1990 (ou seja, em pouco mais de dez anos) cerca de duas dezenas de novos conceitos para designar as mobilizações que surgiram para além do espaço fabril no período. ${ }^{12}$

Este "problema" é mais presente nos meios acadêmicos, embora compareça nas organizações políticas da esquerda brasileira. Muito embora estas, sobretudo os partidos políticos mais consequentes, se caracterizem por formular suas próprias análises acerca das lutas de classes - para as quais partem de determinadas maneiras de entender o capitalismo contemporâneo e suas formas de ser no Brasil, bem como a estrutura de classes decorrente —, me parece justo admitir que a forma turva pela qual boa parte dos cientistas sociais se volta para as "lutas sociais" acaba por turvar também parte das análises que se desenvolvem nas organizações políticas. Refiro-me, especialmente ao debate sobre o sujeito revolucionário, tema tão caro a elas, que é nada menos que um aspecto central para a formulação de estratégias e táticas de ação. Voltarei a isso mais adiante.

\section{Alguns problemas teóricos para pensar as lutas de classes contemporâneas}

Há uma intensa polêmica nas Ciências Sociais, que vem desde os anos 1960 e 1970, acerca das possibilidades políticas de organização e, portanto, de realização de

12. Ana Maria Doimo foi a pesquisadora que nos indicou esse dado em seu importante estudo citado em Braz (2012). Mas suas conclusões acerca do fenômeno são bem diferentes das minhas. 
mediações entre as lutas particulares e a luta política mais ampla. Tal polêmica se desenvolveu ao compasso das metamorfoses sofridas pelo ser das classes trabalhadoras, verificadas a partir das mutações sociais estabelecidas por inúmeras transformações societárias engendradas no âmbito das próprias crises capitalistas, conduzindo-as a um processo geral do que Ruy Braga chamou de restauração do capital. ${ }^{13}$

Tal debate no âmbito das Ciências Sociais contemporâneas opôs o proletariado organizado como movimento operário àqueles movimentos (logo chamados de "novos sujeitos") oriundos de fora do espaço fabril, atinentes às várias instâncias do mundo da reprodução social. ${ }^{14}$

Autores bastante diferenciados como A. Touraine, A. Gorz, A. Bihr, J. Petras, B. S. Santos, D. Bensaid, A. Borón, S Zizek e o brasileiro R. Antunes, apesar de fornecerem interpretações divergentes em muitos aspectos — vejam que, entre eles, há aqueles claramente vinculados à tradição marxista e outros já distantes do/ou contra o marxismo -, apresentam algumas convergências sobre este processo, quais sejam:

a) o consenso em torno da constatação do declínio do movimento operário tradicional em todo o mundo e, em particular, na Europa Ocidental (observado por meio de vários indicadores, como diminuição de greves, das taxas de sindicalização etc.);

b) consequentemente a essa constatação, o consenso em torno da ineficiência dos métodos e dos modelos de organização política adotados até então por tal movimento;

c) a ideia de que as lutas sociais têm crescentemente extrapolado a esfera produtiva stricto sensu, configurando um relativo deslocamento das lutas sociais para a esfera da reprodução social;

d) a noção de que temos, desde os anos 1970, um crescimento indiscutível de "novos sujeitos" portadores de inúmeros interesses, configurando uma verdadeira explosão de novas particularidades sociais.

Por outro lado, a despeito dessas constatações semelhantes, tem se chegado a conclusões e saídas as mais diversas, que se polarizam, basicamente, pela questão

13. A partir deste parágrafo até o primeiro parágrafo da página 17 reproduzo, com alterações, conteúdos que publiquei em Partido e Revolução — 1848-1989 e em Mudanças no perfil das lutas de classes e modismos conceituais: o tormento de Sísifo das ciências sociais (in Bravo, M. I. e Menezes, J. S. B. de [orgs.] Saúde, Serviço Social, Movimentos Sociais e Conselhos. São Paulo: Cortez, 2012).

14. A partir do parágrafo referente a essa nota até o último da página 486 reproduzo, com poucas modificações, os conteúdos presentes em Braz, 2011. 
da centralidade do trabalho como elemento de análise que orienta as reflexões teóricas. A partir desta questão afirma-se, por um lado - aquele que nega a centralidade do trabalho e/ou da classe operária como sujeito político revolucionário (são os casos de Touraine, Gorz e Souza Santos, é o caso também de J. Holloway) —, a impossibilidade da mediação universal (o que significa a inviabilidade do partido como instrumento de mediação universal). Junto a isso, difunde-se uma espécie de supervalorização das particularidades ao mesmo tempo em que se sustenta a inexistência de um elemento universalizante (a classe, especificamente). Cogita-se, no máximo, a existência de uma universalidade humana, assentada, talvez, num humanismo do tipo abstrato. Nesta perspectiva teórica, além da inadmissibilidade da forma partido como o mediador universal, advoga-se certa impossibilidade de unidade ideológica.

Por outro lado - aquele em que a centralidade do trabalho é o ponto de partida, ainda que não necessariamente seja a classe operária o sujeito revolucionário (nesse ponto é que variam as posições de Bihr, Petras, Bensaid, Borón, Antunes e, de modo muito problemático, de Zizek) —, reconhece-se a existência de diversas e complexas particularidades que expressam as inúmeras potencialidades humanas que não inviabilizam a mediação universal, antes a complexifica. Nesta perspectiva, trabalha-se com a centralidade da classe como universalizante dos seres sociais na sociedade capitalista, mesmo diante de sua imensa fragmentação contemporânea. Aqui, parte-se da ideia de que a dissolução da centralidade do trabalho (e da classe) é analítica, e não ontológica.

O desafio consistiria na criação de novas formas de organização política que atuem como elementos de mediação que concorram no universo das várias particularidades no sentido de desfragmentá-las, buscando a sintese fundamental que se dá na mediação universal. Ou seja, o desafio se concentra no problema organziacional, como sugere Netto.

O espectro do debate é bastante amplo e comporta posições que são aparentemente divergentes. Elas confluem em dois aspectos que têm sido aqueles que mais animam (e dividem) as esquerdas contemporâneas. $\mathrm{O}$ primeiro deles refere-se à questão do sujeito revolucionário. O segundo aspecto, cujo debate decorre diretamente do primeiro, diz respeito ao problema do modelo de organismo político universalizador: o partido revolucionário.

O brasileiro Sérgio Lessa levanta a polêmica em torno do chamado "adeus ao proletariado". Sustenta que foram dois os "adeuses ao proletariado": um primeiro ocorrido "sob o impacto da ascensão e crise do Estado de Bem-Estar e do 'fordismo' [...] e um segundo adeus ao proletariado virá à tona nos anos 1990, agora sob o 
impacto da reestruturação produtiva, do neoliberalismo, do pós-modernismo e do fim do bloco soviético (PAG)".

O debate que sugere o sepultamento do proletariado gira em torno de um desenvolvimento de novo tipo das forças produtivas que passariam a ser impulsionadas por modificações técnicas que aprofundam e diversificam as formas de trabalho intelectual (e até mesmo de "trabalho imaterial") operadas pelo capital em seus processos produtivos, provocando, consequentemente, um deslocamento da centralidade das lutas de classes para além do espaço fabril, abrangendo as diversas instâncias da vida cotidiana atinentes à esfera da reprodução social. Esse quadro tornaria a classe operária um segmento condenado ao encolhimento crescente, o que levaria, consequentemente, à perda de sua centralidade política frente a outros estratos de trabalhadores.

Subjacente a esse debate está a questão da ampliação do trabalhador coletivo e, por sua vez, a problemática em torno do trabalho produtivo e do trabalho improdutivo. Lessa sugere que devemos enfrentar um problema teórico que está na necessária distinção entre trabalho produtivo e trabalho e entre trabalho manual e intelectual. A centralidade não está nas relações técnicas de produção, e sim na função social do trabalho (produzir ou não mais-valia).

Segundo Lessa,

um amplo leque de teorias se apoiaram, implícita ou explicitamente, na tese de que o desenvolvimento tecnológico seria o momento determinante das forças produtivas e, portanto, das relações de produção e das classes sociais. Em mais de um momento as hipóteses de que a classe operária estaria extinta ou em extinção, ou então de que estaria se fundindo com o conjunto dos assalariados, têm por fundamento a tese segundo a qual a introdução de novas tecnologias, como a automatização ou a informatização, alteraria o fundamento da relação entre as classes sociais. (2007, p. 39-40)

A consequência mais abrangente desta combinação de fatores - práticos e teóricos - foi a progressiva crise da forma partido como organização política revolucionária precisamente porque se exauriam (também progressivamente) as possibilidades objetivas de revolução e com elas as condições subjetivas que exigiam o protagonismo político do partido. Ademais, somam-se a esse quadro, sintomaticamente contrarrevolucionário, os problemas teóricos no interior dos setores progressistas do pensamento social, conforme mostramos sinopticamente.

A crise que as esquerdas vivem hoje é, sobretudo, uma crise de suas expressões mais avançadas: os movimentos socialista e comunista. Se as suas causas são as 
mais diversas e as mais profundas, suas consequências são (ainda que também profundas) mais evidentes e mais explícitas: veem-se na vitória ideológica do individualismo burguês, na desmobilização social e política das grandes massas trabalhadoras, no desinteresse pelas formas coletivas de participação política e no enfraquecimento das organizações políticas de classe. A crise é maior exatamente nas organizações políticas mais importantes para a emancipação dos trabalhadores, ou seja, nos partidos políticos revolucionários.

O debate atual tem sinalizado uma profunda descrença no partido como instrumento político-organizativo de classe. Esta descrença tem sido convertida em algo mais grave que se expressa em três fenômenos, que guardam diferenças entre eles, mas que estão perfeitamente imbricados: por um lado, na afirmação pura e simples - veiculada pela ideologia dominante e corroborada por uma alegre intelectualidade pós-moderna e por desavisados segmentos de esquerda — da falência (irremediável) do partido como instrumento coletivo de transformação; um segundo fenômeno, que "pega carona" no primeiro e que se espraia também entre a festiva intelectualidade e a desavisada esquerda, parte da constatação da aludida falência e acaba enxergando no fragmento e nas suas formas moleculares de mobilização social a alternativa à crise, ou, pelo menos, uma de suas saídas; por fim, um outro fenômeno se sobrepõe aos outros, tem maior fôlego, goza de maior representatividade e, o que é mais importante, cumpre uma especial funcionalidade política na reprodução da ordem burguesa: trata-se do crescimento de partidos reformistas de todo tipo nas últimas décadas, sejam eles de trabalhadores, trabalhistas, socialistas, social-democratas ou mesmo os de corte operário e, nalguns poucos casos, os próprios partidos comunistas. A lista é vastíssima e variada; os exemplos são igualmente diversificados.

Cumpre asseverar que tanto mais se afirmava a crise dos movimentos socialista e comunista mais se intensificaram os fenomenos supracitados e, com eles, mais se afundavam os partidos revolucionários numa crise que é, simultaneamente, de legitimidade, de base social, de definição de objetivos estratégicos, em suma, uma crise de projeto societário.

A crise expressou o desmoronamento das experiências revolucionárias edificadas ao longo do século XX. Junto com o fim da União Soviética esgotaram-se também as experiências dos países do Leste Europeu que constituíam o chamado "bloco socialista", restando apenas, fora daquele continente, a resistência da Revolução Cubana, para não mencionar o exemplo problemático da Coreia do Norte e da já capitalista China. Por outro lado, como já apontei, ocorreu um processo de ascensão de formatos partidários reformistas de todo tipo que levou de roldão o que restou de partidos comunistas. 
Este cenário requer repensar a questão do partido a partir de duas questões fundamentais que compõem o núcleo central da argumentação. Primeiro, a ideia de que todas as revoluções proletárias desenvolvidas ao longo do século $X X$ se caracterizaram por dois aspectos determinantes: ou tiveram os partidos políticos (socialistas ou comunistas) como um dos seus principais protagonistas desde a preparação do processo revolucionário, passando pelo seu desenlace decisivo e se prolongando pela sua afirmação e consolidação; ou as revoluções acabaram por engendrá-los ulteriormente, como seu desdobramento político, tendo-os como um dos seus principais condutores. Segundo, a constatação de que a partir das próprias revoluções se consolidou, no quadro da tradição marxista, toda uma tradição teórico-política voltada para o debate em torno da concepção de revolução e da noção de partido revolucionário; tal tradição deu continuidade — aprofundando, inovando, revisando ou deformando - aos debates que se iniciaram na segunda metade do século XIX.

E essa exigência de repensar o partido não deve atender a nenhuma dogmática. Ela deve atender, sim, a duas condições. Primeiro, a de afirmar o papel fundamental da teoria, da sua atualização frente aos desafios atuais. Segundo, a de que se deve afirmar no interior de qualquer organização política que se pretenda revolucionária, os princípios fundamentais que estão postos no Manifesto do Partido Comunista, quais sejam: o combate permanente à propriedade privada dos meios de produção fundamentais; a unidade das forças políticas de esquerda e progressistas; a propaganda e formação políticas voltadas para o desenvolvimento da consciência de classe; o internacionalismo proletário que envolva as mediações dos aspectos nacionais das lutas de classes.

Sem pretensões de fornecer respostas definitivas a esse debate, prefiro concluir com o seguinte raciocínio de Marx quando criticou as formas de socialismo de seu tempo. Para ele, as fragilidades das proposições socialistas se deviam às próprias debilidades do proletariado que se formava. Disseram ele e Engels no Manifesto: "a importância do socialismo utópico é inversamente proporcional ao desenvolvimento histórico do proletariado". Ou seja, a importância de todo tipo de negação do partido em nome de um utópico movimentismo que conhecemos na atualidade é inversamente proporcional ao amadurecimento histórico do processo revolucionário.

É certo que devemos atuar pela superação de nosso deficit organizacional, mas sem incorrer no equívoco de criar modelos preestabelecidos para ser encaixados na realidade. Talvez o melhor caminho seja o que sugere Lukács, para quem "a questão da organização de um partido revolucionário só se pode desenvolver a partir de uma teoria da própria revolução. Só quando a revolução entra na ordem 
do dia é que a questão da organização revolucionária irrompe com imperiosa necessidade nas consciências das massas e dos seus porta-vozes teóricos" (Lukács, 1974, p. 305).

\section{IV}

\section{A necessidade de superar as ilusões (e as condições) do nosso tempo}

O amadurecimento histórico do proletariado não cairá dos céus e nem se dará pela ação natural do tempo. Ele precisa ser acelerado pelos segmentos mais conscientes que lutam ao lado dos trabalhadores e que se encontram preponderantemente nos partidos ligados ao prolateriado, tanto os de corte socialista quanto os efetivamente comunistas. Todavia, é necessário que se tenha a absoluta clareza de que a reafirmação do partido como a organização política primordial da transformação social em pleno século XXI se inscreve num caldo ideocultural muito adverso a ele. E parece claro também que sua reafirmação é uma atitude explícita de confronto contra o pensamento dominante — de esquerda e de direita - justamente por se tratar de uma defesa que navega na contracorrente. Mas, infelizmente, não é só isso! Para as gerações atuais, tal tarefa se expressa como um enorme desafio teórico! Ela exige de nós um esforço de superação das debilidades da nossa própria formação sociocultural, que são, na verdade, debilidades de toda uma geração.

Tais debilidades dizem respeito não às fragilidades e lacunas teóricas que todos temos, em menor ou maior grau. Dizem respeito, principalmente, aos limites culturais de uma época, aos acidentes históricos de um tempo que foi legado a nós e a nossa geração - os "tempos conservadores" de Agustín Cueva. Esse legado histórico se coloca a nós não como um "pesadelo das gerações mortas a atormentar o cérebro dos vivos", mas como a necessidade de despertar de um sono tão profundo que, mesmo depois de acordados, ainda turva nossos olhos. Falo de um tempo histórico do "presentismo" (Hobsbawm), que quer arrancar de nós a história, que nega até mesmo a razão. Para o gênero humano esse é o pior cenário, e já sabemos aonde ele nos leva. Goya foi certeiro quando disse: "El sueño de la razón produce monstruos".

As circunstâncias que encontramos para "fazer história" embaçam a "poesia do futuro" que, como tal, não pode ser simplesmente a reposição da poesia do passado e não pode se limitar ao imediato presentismo, que é algo muito aquém da 
centralidade ontológica do presente que há na teoria social marxiana. Tanto o presentismo quanto a nostalgia do passado são formas a-históricas que conduzem ou ao messianismo ou à inação. No caso dessa "perspectiva nostálgica", como observou um importante marxista, "pretende-se criticar o evolucionismo, mas a crítica atinge também a própria dialética: o vir-a-ser e a bela imagem do tempo como espiral, como 'círculo de círculos', são substituídos pelo deixar-de-ser e pela esperança messiânica da redenção que retira suas forças dos sonhos (portanto: apenas da esfera subjetiva) que o passado sepultou" (Frederico, 2005, p. 17).

O pensamento social atual está prenhe de perspectivas que negam o caráter progressivo do desenvolvimento material da humanidade. Tal negação se expressa numa crítica ao progresso, a qual se confunde com a crítica generalizada àquele desenvolvimento que é, antes de tudo, expressão dos avanços contraditórios da humanidade que, à medida que realiza mudanças, muitas vezes imperceptíveis, provocadas pela busca incessante por satisfazer suas necessidades sociais históricas, acaba por acumular saltos qualitativos. Tais saltos não se dão numa linearidade. A história não é linear e nem opera seguindo nenhum padrão evolucionista que paire acima dela. Mas a história se expressa na ininterrupta superação dos obstáculos naturais que se colocam diante da existência social dos homens, permitida pelo constante revolucionamento das forças produtivas que estão pressionando permanentemente as relações sociais de produção, num choque inadiável, mas controlado, pois que não pode derruir as formas jurídicas nas quais se assentam aquelas relações. A observação de um conhecido estudioso do método de Marx é precisa: "sem progressão, a história torna-se um tempo saturado de 'agoras"' (Idem).

Contudo, essa mesma época e tempo históricos - que julguei, junto a tantos outros analistas, contrarrevolucionários e conservadores - nos permitem hoje, graças à limitada democracia conquistada pela luta de tantos brasileiros, estar aqui tratando abertamente de temas como partido e revolução. Por outro lado, esse mesmo tempo histórico quer nos conduzir à capitulação, convida-nos ao desencanto, deseja nos seduzir com o facilitismo e com o possibilismo (variávies do oportunismo), apresenta-nos o "canto da sereia" da vida acadêmica, oferece-nos a prostituição do dinheiro e, finalmente, quer nos fazer crer no fim das ideologias, das lutas de classes, do partido e da própria revolução. Não basta apenas dizer-nos não a esse estado de coisas! Não basta apenas resistir, ainda que seja preciso. É necessário superar o simples não e ir além da resistência. É preciso que encontremos os caminhos para suplantar de uma só vez as ilusões de nossos tempos. Antes disso, devemos buscar superar as condições que as criam, num sentido tão claro como 
o que aparece nas palavras de Marx para quem "a necessidade de abandonar uma ilusão acerca de determinada condição é, antes de tudo, a necessidade de abandonar uma condição que necessita de ilusões".

\section{Recebido em 14/6/2012 - Aprovado em 19/6/2012}

\section{Referências bibliográficas}

ANTUNES, R. Adeus ao trabalho? São Paulo: Cortez, 1995.

BENSAID, D. Marx, o intempestivo: grandezas e misérias de uma aventura crítica (séculos XIX e XX). Rio de Janeiro: Civilização Brasileira, 1999.

2008.

. Os irredutíveis: teoremas da resistência para o tempo presente. São Paulo: Boitempo,

BIHR, A. Da grande noite à alternativa. São Paulo: Boitempo, 1999.

BLACKBURN, R. (Org.). Depois da queda. Rio de Janeiro: Paz e Terra, 1993.

BORÓN, A. O socialismo do século XXI. São Paulo: Expressão Popular, 2010.

BRAGA, R. A restauração do capital. Um estudo sobre a crise contemporânea. São Paulo: Xamã, 1996.

BRAZ, M. Mudança no perfil das lutas de classes e modismos conceituais: o tormento de Sísifo das Ciências Sociais. In: BRAVO, M. I. S.; MENESES, J. B. Saúde, Serviço Social, movimentos sociais e conselhos. São Paulo: Expressão Popular, 2012.

. Partido e revolução: 1848-1989. São Paulo: Expressão Popular, 2011.

. Apresentação. In: LENIN, V. Que fazer? Problemas candentes do nosso movimento.

Trad. M. Braz. São Paulo: Expressão Popular, 2010.

CASTELO, R. (Org.). Encruzilhadas da América Latina no século XXI. Rio de Janeiro: Pão e Rosas, 2010.

. As encruzilhadas da América Latina no século XXI. Rio de Janeiro: Pão e Rosas, 2011.

CLAUDÍN, F. A crise do movimento comunista. São Paulo: Global, 1985-1986. v. 1-2.

COUTINHO, C. Marxismo e politica. São Paulo: Cortez, 1994.

DOIMO, A. M. A vez e voz do popular: movimentos sociais e participação política no Brasil pós-70. Rio de Janeiro: Relume-Dumará/Anpocs, 1995.

FREDERICO, C. Crise do socialismo e movimento operário. São Paulo: Cortez, 1994. 
FREDERICO, C. Marx, Lukács: a arte na perspectiva ontológica. Natal: EdUFRN, 2005.

GORZ, A. Adeus ao proletariado: para além do socialismo. Rio de Janeiro: Forense, 1982.

GUSTAFSSON, B. Marxismo y revisionismo: la critica bernsteiniana del marxismo y sus premisas historico-ideológicas. Barcelona/Buenos Aires/Mexico: Grijalbo, 1975.

HARVEY, D. et al. Occupy: movimentos de protesto que tornaram as ruas. São Paulo: Boitempo/ Carta Maior, 2012.

HOBSBAWM, E. O marxismo hoje: um balanço aberto. In: . História do marxismo XI: o marxismo hoje (Primeira Parte). Rio de Janeiro: Paz e Terra, 1983.

HOLLOWAY, J. Partidos políticos?, Margem Esquerda, São Paulo, n. 4, 2004.

KURZ, R. O colapso da modernização: da derrocada do socialismo de caserna à crise da economia mundial. Rio de Janeiro: Paz e Terra, 1992.

KOHEN, A. La izquierda y los nuevos tiempos. Buenos Aires: Antarca, 1987.

LENIN, V. I. Obras escolhidas. São Paulo: Alfa-Ômega, 1979. T. 1, 2, 3.

LESSA, S. Trabalho e proletariado no capitalismo contemporâneo. São Paulo: Cortez, 2007.

LUKÁCS, G. História e consciência de classe. Lisboa: Escorpião, 1974.

. A decadência ideológica e as condições gerais da pesquisa científica: In: Lukács.

São Paulo: Ática; n. 20, 1992. (Col. Grandes cientistas sociais)

MANDEL, E. O capitalismo tardio. São Paulo: Abril Cultural, 1982. (Col. Os economistas.)

MARX, K. Manifesto do partido comunista. São Paulo: Cortez, 1998. . Miséria da filosofia. São Paulo: Livraria Exposição do Livro. (s/d.) ; ENGELS, F. Obras escolhidas. São Paulo: Alfa-Ômega, T. 1, 2, 3. (s/d.)

MÉSZÁROS, I. Para além do capital. São Paulo: Boitempo; Campinas: Ed. Unicamp, 2002. . O século XXI. Socialismo ou barbárie? São Paulo: Boitempo, 2003.

NETTO, J. P. Crise do socialismo e ofensiva neoliberal. São Paulo: Cortez, 1993.

. O deficit da esquerda é organizacional, Socialismo e Liberdade. Rio de Janeiro, ano 1, n. 2, 2009.

; BRAZ, M. Economia política: uma introdução crítica. 7. ed. São Paulo: Cortez, 2011.

OLIVEIRA, F. et al. (Orgs.) Hegemonia às avessas. São Paulo: Boitempo, 2007.

. Hegemonia às avessas. Economia, política e cultura na época da servidão financeira. São Paulo: Boitempo, 2010.

PETRAS, J. Neoliberalismo: América Latina, Estados Unidos e Europa. Blumenau: Furb, 1999. 
POCHMANN et al. (Orgs.). Atlas da exclusão social: os ricos no Brasil. 2. ed. São Paulo: Cortez, 2005. v. 3.

SADER, E. (Org.). O mundo depois da queda. Rio de Janeiro: Paz e Terra, 1995.

SANTOS, B. S. Pela mão de Alice: o social e o político na pós-modernidade. São Paulo: Cortez, 1999.

TOGLIATTI, P. Socialismo e democracia: escritos escolhidos do período 1944/1964. Rio de Janeiro: Edições Muro, 1980.

TOURAINE, A. A sociedade pós-industrial. Lisboa: Moraes, 1970.

ZIZEK, S. Às portas da revolução. Escritos de Lênin de 1917. São Paulo: Boitempo, 2005. . Primeiro como tragédia, depois como farsa. São Paulo: Boitempo, 2011. 